
\title{
Pattern of Non-Adherence to Statins in Patients of Dominican Descent in an Outpatient Setting
} Constantine E. Kosmas ${ }^{* 1}$, Rosmery Morcelo ${ }^{2}$, Ian Martinez ${ }^{2}$, Digna Rosario ${ }^{3}$, Nolberto Hernandez 2 , Peter D. Montan ${ }^{2}$, and Eliscer Guzman ${ }^{4}$

${ }^{I}$ Department of Medicine, Division of Cardiology, Mount Sinai Hospital, New York, NY, USA

${ }^{2}$ Cardiology Clinic, Cardiology Unlimited, PC, New York, NY, USA

${ }^{3}$ Department of Pediatrics, Lincoln Medical Center, Bronx, NY, USA

${ }^{4}$ Department of Medicine, Division of Cardiology, Montefiore Medical Center, Bronx, NY, USA

"Corresponding author: Constantine E. Kosmas, MD, PhD, 168-24 Citation: Kosmas CE, Morcelo R, Martinez I, Rosario D, Hernandez N, Powells Cove Blvd., Beechhurst, NY 11357. E-mail: cekosmas1@gmail. Montan PD, and Guzman E (2017) Pattern of Non-Adherence to Statins in com Patients of Dominican Descent in an Outpatient Setting. Enliven: Clin Cardiol

Received Date: $25^{\text {th }}$ September 2017

Accepted Date: $30^{\text {th }}$ October 2017

Published Date: $07^{\text {th }}$ November 2017

Res 4(1): 001.

Copyright: @2017 Constantine E.Kosmas. This is an Open Access article published and distributed under the terms of the Creative Commons Attribution License, which permits unrestricted use, distribution and reproduction in any medium, provided the original author and source are credited

\begin{abstract}
Statins are the standard of care in the management of hypercholesterolemia and there is extensive clinical evidence demonstrating their efficacy in lowering LDL cholesterol and decreasing cardiovascular risk. However, several trials have shown that non-adherence to statin therapy is a relative common issue that may lead to adverse cardiovascular outcomes. Side effects, mostly myalgias, are in general cited as the most common cause of statin discontinuation but other factors may include unfounded fear of side effects, low education and/or low socioeconomic status, patient desire for alternative and/or natural medicines, multiple comorbidities and polypharmacy. Furthermore, age and ethnicity may also play a role in adherence to statins. We performed an observational, cross-sectional study monitoring adherence to statins in 445 patients of Dominican decent in an outpatient setting in a Cardiovascular Clinic and a Lipid Clinic (located in the same medical building).The rate of non-adherence to statins was $24.49 \%$ and non-adherence was more common among the patients seen in the Cardiovascular Clinic, as compared to those seen in Lipid Clinic. The most common causes of nonadherence were forgetting to take the medication, fear of side effects, true reported side effects and running out of medication or refills. Other contributing factors are also discussed in detail in our manuscript. These factors need to be considered in devising approaches to enhance adherence to guideline-based therapies.
\end{abstract}

Keywords: Statins; Cardiovascular disease; Non-adherence; Dominican ethnicity

\section{Introduction}

Cardiovascular disease (CVD) is the leading cause of death worldwide, causing $30 \%$ of the annual global mortality [1]. In the United States, where the disease is highly prevalent, over one third of the population has CVD [2]. Dyslipidemia is one of the major CVD risk factors and cholesterolmodifying therapy has well-established benefits in both the primary [3] and secondary [4] prevention.

Statins are the standard of care in the management of hypercholesterolemia and their effectiveness in lowering Low-Density Lipoprotein Cholesterol (LDL-C) and reducing cardiovascular risk has been demonstrated in multiple clinical trials $[5,6]$.

Notwithstanding, despite the exorbitant trial evidence that statin therapy is very effective in reducing cardiovascular morbidity and mortality both in primary and secondary prevention, the effectiveness of statins may be significantly compromised by poor adherence [7-9]. In the West of Scotland Coronary Prevention Study (WOSCOPS), only $38.7 \%$ of the patients in the original statin group were still receiving a statin 5 years after the completion of the trial [8]. In another study with a median follow-up of 4.1 years, the rate of non-adherence to statins was $26 \%$. This led to an $85 \%$ increase in all-cause mortality and a $62 \%$ increase in cardiovascular mortality [9].

The causes of non-compliance are multifactorial and may include true statin-related side effects, such as myalgias, lack of education and awareness about the long-term benefits of treatment, but also unfounded misconceptions and/or fear about side effects, by both the patients and some physicians, which are not supported by recent large randomized trials [7]. Other reported factors that may potentially lead to non-adherence to statins include younger age, female gender, African American or Hispanic ethnicity, 
the presence of multiple comorbidities, lower socioeconomic status, cost of the medication and lack of insurance coverage [7,10]. Furthermore, the lack of any apparent immediate benefit, from the patient's perspective, may play an important role in the adherence of the patient to the medication. In one trial, which compared the patient's adherence to statins versus oral antihyperglycemic therapy, the proportion of patients with a 2-year medication possession ratio (MPR) $>80 \%$ was $52 \%$ for statin versus $63 \%$ for oral antihyperglycemic therapy $(\mathrm{P}<0.0001)$. The median time to discontinuation of statin therapy was also significantly shorter compared with oral antihyperglycemic therapy ( 284 vs 495 days; $\mathrm{P}<0.001$ ). There was a $47 \%$ greater risk to discontinue statin than oral anti-hyperglycemic therapy [11].

Our small pilot study aims to describe the pattern of compliance to statins in a community of Dominican descent, in an outpatient setting, attempting to identify its prevalence, causes of non-adherence, and the role of the specific setting that a patient is being assessed (Cardiovascular Clinic versus Lipid Clinic).

Patients and Methods

An observational cross-sectional study was performed in an outpatient setting in a Cardiovascular Clinic and a Lipid Clinic (located in the same medical building) from the period of July 2016 to June 2017. The study included 445 patients (190 men, 255 women) of Dominican descent, who have been previously prescribed a statin for the treatment of hypercholesterolemia. The patients responded to a simple questionnaire regarding compliance to their statin and, if they were not compliant, what was the specific reason of nonadherence. Non-adherence was defined as missing statin therapy for a period of 7 days or more. The reports of the pertinent laboratory data were also used to document non-adherence. The data were then compiled and analyzed in Microsoft Excel 2016.
Results

After compilation and review of the obtained data, analysis of our sample of 445 patients revealed that 109 patients $(24.49 \%)$ were non-adherent to statins, while the rest 336 patients $(75.51 \%)$ were adherent (Table 1$)$.

The rate of non-adherence to statin therapy was greater among the patients assessed in the Cardiovascular Clinic (99 of 387 patients; 25.58\%), as compared to the rate of non-adherence of the patients seen in the Lipid Clinic (10 of 58 patients; $17.24 \%$ ) (Table 2).

The rate of non-adherence with statin therapy was lower in patients older than 65 years of age ( 55 of 260 patients; $21.15 \%$ ), as compared to the rate of non-adherence of patients $\leq 65$ years of age (54 of 185 patients; $29.19 \%$ ) (Table 3).

The rate of non-adherence to statin therapy was similar amongst men and women (47 of 190 patients; $24.74 \%$ versus 62 of 255 patients; $24.31 \%$, respectively) (Table 4).

The main causes of non-adherence to statins in our study population of Dominican descent were forgetting to take the medication (21 of 109 patients; 19.27\%), fear of side effects (20 of 109 patients; 18.35\%), reported true statin side effects (15 of 109 patients; 13.76\%), running out of medication or running out of refills (13 of 109 patients; 11.93\%) and complains about polypharmacy (12 of 109 patients; $11.01 \%$ ). Other less common reasons for non-adherence to statins, included the discontinuation of the statin after normalization of cholesterol levels, the preferential use of natural supplements or other arbitrary dietary regimens, as well as the lack of insurance coverage or other cost-related issues (Table 5).

Table 1: Patients status - adherence to statins.

\begin{tabular}{|l|l|l|}
\hline \multicolumn{2}{|c|}{ Patients' Adherence to statins } \\
\hline Adherent & $336 / 445$ & $75.51 \%$ \\
\hline Non-adherent & $109 / 445$ & $24.49 \%$ \\
\hline
\end{tabular}

Table 2: Clinical adherence assessment

\begin{tabular}{|l|l|l|}
\hline \multicolumn{3}{|c|}{ Non-Adherence - Assessment Setting } \\
\hline Cardiovascular Clinic & $99 / 387$ & $25.58 \%$ \\
\hline Lipid Clinic & $10 / 58$ & $17.24 \%$ \\
\hline
\end{tabular}

Table 3: Adherence assessment according to age

\begin{tabular}{|l|l|l|}
\hline \multicolumn{3}{|c|}{ Age and Non-Adherence } \\
\hline$>65 \mathrm{yrs}$ & $55 / 260$ & $21.15 \%$ \\
\hline$\leq 65 \mathrm{yrs}$ & $54 / 185$ & $29.19 \%$ \\
\hline
\end{tabular}

Table 4: Adherence assessment according to sex

\begin{tabular}{|l|l|l|}
\hline \multicolumn{3}{|c|}{ Sex and Non-Adherence } \\
\hline $\mathrm{M}$ & $47 / 190$ & $24.74 \%$ \\
\hline $\mathrm{F}$ & $62 / 255$ & $24.31 \%$ \\
\hline
\end{tabular}


Table 5: Non-adherence causes

\begin{tabular}{|l|l|l|}
\hline Causes of Non-Adherence & & \\
\hline Forgetting to take the medication & $21 / 109$ & $19.27 \%$ \\
\hline Fear of side effects & $20 / 109$ & $18.35 \%$ \\
\hline Side effects of the medication & $15 / 109$ & $13.76 \%$ \\
\hline Running out of medication or running out of refills & $13 / 109$ & $11.93 \%$ \\
\hline Too many medications (Poly pharmacy) & $12 / 109$ & $11.01 \%$ \\
\hline Cholesterol normalized and statin was stopped & $9 / 109$ & $8.26 \%$ \\
\hline Use of natural supplements or other arbitrary dietary regimens & $6 / 109$ & $5.50 \%$ \\
\hline Lack of insurance coverage or other financial issues & $3 / 109$ & $2.75 \%$ \\
\hline
\end{tabular}

\section{Discussion}

The statin non-adherence rate in our population of Dominican descent was $24.49 \%$ among the 445 patients enrolled in this cross-sectional, observational study. Although direct comparisons cannot be made, our study comes to confirm one more time in this Dominican population that the rates of noncompliance to statins remain high, as it has been shown in previous larger studies in diverse patient populations [8,9,12-15].

In our study, we observed better patient adherence in the group of patients evaluated in the Lipid Clinic rather than in the Cardiovascular Clinic. Although the results did not quite reach statistical significance, mainly due to the small total number of subjects, this observation clearly suggests that spending more time with a patient to specifically and in detail address the lipid issue (as it occurs in the Lipid Clinic), rather than discussing the lipid problem only as part of multiple other cardiovascular issues (as it occurs in the Cardiovascular Clinic), may significantly improve compliance to lipid-lowering therapy. This observation is also supported by previous comprehensive evidence [16].

Age has been cited as an important factor that may affect the adherence to statins. In a large meta-analysis, age was found to have a U-shaped association with adherence to statins; the oldest ( $\geq 70$ years) and youngest ( $<50$ years) had lower adherence, as compared to the middle aged (50-69 years) participants [17]. In another large study, however, younger age was associated with lower adherence to statins [10]. In our study, the older patients ( $>65$ years) were more compliant to statins, as compared to younger patients ( $\leq 65$ years) [Rates of non-adherence of $21.15 \%$ versus $29.19 \%$, respectively]. One factor potentially responsible for this observation may be that elderly patients are more concerned about their health, given also their past experiences of CVD events, while younger people may exhibit a more "care-free" attitude. Furthermore, in general, Hispanic communities are consisted mostly of nuclear families, where the children and grandchildren are usually the caretakers and they are very keen on assuring that their parents and grandparents are fully compliant with their medical therapy.

Among the causes of non-compliance to statins in our study, forgetting to take the medication was the most common one $(19.27 \%$ of non-compliant subjects). However, a very close second in frequency cause of non-adherence (18.35\% of non-compliant subjects) was the unfounded fear of side effects of the medications, which is not supported by clinical evidence from large randomized trials [7]. Unfounded fears and misconceptions may be created or exacerbated by information found on the Internet and other media, which may describe the "worst case scenario" or exaggerate the risks of therapy. This has also been reported in previous studies addressing statin nonadherence $[7,18,19]$. In our small study in patients of Dominican descent, true reported side effects (mostly myalgias) were responsible for only $13.76 \%$ of the cases of non-adherence to statins. This is in contrast to the results of a large survey of statin users, where muscle-related side effects were reported by $60 \%$ and $25 \%$ of former and current users, respectively, and the primary reason for discontinuation of the statins was side effects of the medication ( $62 \%$ of cases) [20].

In conclusion, consistent with previous studies in diverse patient populations, the rate of non-adherence to statins was quite high in our small study population of Dominican descent, as approximately one quarter of the participants did not comply with their statin therapy. As statin non-adherence has been linked to adverse cardiovascular outcomes, it is imperative that aggressive efforts should be made to improve compliance. Again, the fact that compliance was better in the patients seen in the Lipid Clinic clearly indicates that spending more time with the patients to address their specific lipid-related issues and answer all their relevant questions would be a very promising intervention to improve adherence to statins.

Finally, limitations of our study are the relatively small number of subjects, which did not permit to obtain fully statistically significant results, as well as the fact that the time interval from the initial prescription of the statin to the day of the patient's evaluation in the clinic was not taken into account. Another limitation of our study is that persistence to statin therapy was not addressed in our study. Nevertheless, our study did reveal significant trends into the pattern of non-adherence to statins in patients of Dominican descent.

\section{References}

1. Roth GA, Johnson C, Abajobir A, Abd-Allah F, Abera SF, et al. (2017) Global, Regional, and National Burden of Cardiovascular Diseases for 10 Causes, 1990 to 2015. J Am Coll Cardiol 70: 1-25.

2. Writing Group Members, Mozaffarian D, Benjamin EJ, Go AS, Arnett DK, et al. (2016) American Heart Association Statistics Committee; Stroke Statistics Sub committee. Heart Disease and Stroke Statistics-2016 Update: A Report From the American Heart Association. Circulation 133: e38-e360.

3. O'Keefe JH Jr, Cordain L, Harris WH, Moe RM, Vogel R et al. (2004) Optimal low-density lipoprotein is 50 to $70 \mathrm{mg} / \mathrm{dl}$ : lower is better and physiologically normal. J Am Coll Cardiol 43: 2142-2146. 
4. LaRosa JC, Grundy SM, Waters DD, Shear C, Barter P, et al. (2005) Treating to New Targets (TNT) Investigators. Intensive lipid lowering with atorvastatin in patients with stable coronary disease. N Engl J Med 352: $1425-1435$.

5. Waters DD (2006) What the statin trials have taught us. Am J Cardiol 98: 129-134.

6. Grundy SM, Cleeman JI, Merz CN, Brewer HB Jr, Clark LT, et al. (2004) National Heart, Lung, and Blood Institute; American College of Cardiology Foundation; American Heart Association. Implications of recent clinical trials for the National Cholesterol Education Program Adult Treatment Panel III guidelines. Circulation 110: 227-239.

7. Lardizabal JA, Deedwania PC (2010) Benefits of statin therapy and compliance in high risk cardiovascular patients. Vasc Health Risk Manag 6:843-853.

8. Ford I, Murray H, Packard CJ, Shepherd J, Macfarlane PW, et al. (2007) West of Scotland Coronary Prevention Study Group. Long-term followup of the West of Scotland Coronary Prevention Study. N Engl J Med 357: 1477-1486.

9. Ho PM, Magid DJ, Shetterly SM, Olson KL, Maddox TM, et al. (2008) Medication non adherence is associated with a broad range of adverse outcomes in patients with coronary artery disease. Am Heart J 155: 772779.

10. Yang Y, Thumula V, Pace PF, Banahan BF 3rd, Wilkin NE, et al. (2009) Predictors of medication non adherence among patients with diabetes in Medicare Part D programs: a retrospective cohort study. Clin Ther. 31: 2178-2188.

11. Zhang Q, Zhao C, Davies MJ, Radican L, Seck T (2011) Compliance and persistence with concomitant statin and oral anti hyperglycemic therapy. Am J Manag Care 17: 746-752.
12. Benner JS, Glynn RJ, Mogun H, Neumann PJ, Weinstein MC (2002) Long-term persistence in use of statin therapy in elderly patients. JAMA 288: 455-461.

13. Shah ND, Dunlay SM, Ting HH, Montori VM, Thomas RJ (2009) Longterm medication adherence after myocardial infarction: experience of a community. Am J Med 122: e7-e13.

14. Glader EL, Sjölander M, Eriksson M, Lundberg M (2010) Persistent use of secondary preventive drugs declines rapidly during the first 2 years after stroke. Stroke 41: 397-401.

15. Donnelly LA, Doney AS, Morris AD, Palmer CN, Donnan PT (2008) Longterm adherence to statin treatment in diabetes. Diabet Med 25: 850-855.

16. Maningat P, Gordon BR, Breslow JL (2013) How do we improve patient compliance and adherence to long-term statin therapy? Curr Atheroscler Rep. 15: 291.

17. Mann DM, Woodward M, Muntner P, Falzon L, Kronish I (2010) Predictors of non adherence to statins: a systematic review and metaanalysis. Ann Pharmacother 44: 1410-1421.

18. Tolmie EP, Lindsay GM, Kerr SM, Brown MR, Ford I (2003) Patients' perspectives on statin therapy for treatment of hyper cholesterolaemia: a qualitative study. Eur J Cardiovasc Nurs 2: 141-149.

19. Mann DM, Allegrante JP, Natarajan S, Halm EA, Charlson M (2007) Predictors of adherence to statins for primary prevention. Cardiovasc Drugs Ther 21: 311-316.

20. Cohen JD, Brinton EA, Ito MK, Jacobson TA (2012) Understanding Statin Use in America and Gaps in Patient Education (USAGE): an internet-based survey of 10,138 current and former statin users. J Clin Lipidol 6: 208-215.

Submit your manuscript at http://enlivenarchive.org/submit-manuscript.php New initiative of Enliven Archive

Apart from providing HTML, PDF versions; we also provide video version and deposit the videos in about 15 freely accessible social network sites that promote videos which in turn will aid in rapid circulation of articles published with us. 